\title{
Economic Burden of Illness in Adult Patients with Nocturia
}

\author{
Roger Dmochowski, MD; Benjamin M. Brucker, MD; Emily Cole, MD; Steve Kawahara, PharmD, BCACP; \\ Riya Pulicharam, MD; Caroline Burk, PharmD, MS; Amy Tung, PharmD, MS; and Douglass Hale, MD
}

\begin{abstract}
BACKGROUND: Nocturia is considered to be a very bothersome lower urinary tract disorder. Yet, to date, the economic burden attributable to this poor health condition remains less well known.

OBJECTIVE: To compare differences in health care resource utilization (HCRU), health care costs, and work productivity in adult patients with differing frequencies of nocturia episodes (i.e., $<2$ vs. $\geq 2$ nocturia episodes per night).

METHODS: Adult patients with nocturia enrolled in an integrated proprietary database were recruited to complete a survey on their demographics, nocturia characteristics, and work productivity. Using patients' survey data and health care claims from the previous 6 months, those with $<2(n=197$; $21.9 \%$ ) versus $\geq 2$ ( $n=702 ; 78.1 \%)$ nocturia episodes per night were compared for differences in HCRU, health care costs, and work productivity after adjusting for potential confounders. HCRU was reported as the mean number per patient per month (PPPM) for outpatient visits (all types), physician office visits, and prescriptions filled and the proportion of patients with $\geq 1$ hospitalization or emergency department visit in the previous 6 months. Health care costs were reported as mean PPPM. Work productivity was assessed via patient survey and reported as a mean percentage for absenteeism, presenteeism, overall work impairment, and activity impairment during the past week.
\end{abstract}

RESULTS: 899 adult patients (mean age $=71.4$ years; $57.2 \%$ men) were enrolled and analyzed. Compared with patients with $<2$ nocturia episodes per night, patients with $\geq 2$ nocturia episodes had more outpatient health care visits (unadjusted mean visits PPPM: 2.1 vs. $1.6 ; P<0.001$; adjusted mean visits PPPM: 2.1 vs. $1.6 ; P=0.017$ ), office visits (unadjusted and adjusted mean visits PPPM: 0.9 vs. $0.7 ; P<0.001$ ), and prescriptions filled (unadjusted mean prescription fills PPPM: 3.1 vs. $2.1 ; P<0.001$; adjusted mean prescription fills PPPM: 3.2 vs. $2.2 ; P=0.027$ ). Patients with $\geq 2$ nocturia episodes per night also displayed significantly higher outpatient health care costs (unadjusted mean PPPM costs: $\$ 676$ vs. $\$ 516$; $P=0.028$; adjusted mean PPPM costs: $\$ 678$ vs. $\$ 506 ; P=0.017$ ). In terms of work productivity impairment, patients with $\geq 2$ nocturia episodes per night experienced higher rates of unadjusted (20\% vs. $10 \% ; P=0.002)$ and adjusted presenteeism ( $20 \%$ vs. $10 \% ; P=0.004)$ and unadjusted $(20 \%$ vs. $10 \% ; P=0.002)$ and adjusted overall work impairment ( $20 \%$ vs. $10 \% ; P=0.001)$.

CONCLUSIONS: Study findings demonstrate that nocturia was associated with higher outpatient encounters and related costs in the presence of a greater occurrence of nocturic episodes.

J Manag Care Spec Pharm. 2019;25(5):593-600

Copyright @ 2019, Academy of Managed Care Pharmacy. All rights reserved.

\section{What is already known about this subject}

Nocturia is a particularly bothersome condition that affects a substantial portion of the U.S. adult population.

Understanding the economic burden of nocturia is crucial for informing patients and payers of its associated direct and indirect costs

\section{What this study adds}

The presence of 2 or more nocturic episodes per night was associated with higher outpatient health care-related costs and a diminution in work productivity and daily activities.

These observations underscore the notable economic and societal implications that are perhaps attributable to an increased occurrence of nocturic episodes.

$\mathrm{N}$ octuria is a condition involving excessive urination at night. Although defined as waking $\geq 1$ time at night to void, nocturia is considered by some authorities as clinically significant at $\geq 2$ voids per night. ${ }^{1,2}$ Nocturia prevalence in the United States is estimated to be $20 \%$ in women and $15 \%$ in men and increases with advancing age. ${ }^{3}$ An estimated $58 \%$ of women and $66 \%$ of men between the ages of 50 and 59 years, in addition to $72 \%$ of women and $91 \%$ of men $>80$ years of age, present with nocturia. ${ }^{4}$

Nocturia's clinical features are largely equivalent among women and men, with underlying causes often a consequence of nocturnal polyuria (i.e., increased urinary output during the nighttime), overactive bladder (OAB; i.e., urge to urinate due to involuntary contractions of the bladder muscles), and complications related to bladder storage and sleep disorders. ${ }^{4}$ Clinical documentation of nocturia is thought to be associated with how bothersome it is to the individual, with severity of symptoms linked to the frequency of nocturnal micturition. Although nocturia predominantly influences sleep, it is also presumed to negatively affect daytime well-being, functioning, and productivity. ${ }^{5,6}$ Conservative management of nocturia typically involves modification of fluid intake and timing of diuretic administration, compression stockings and leg elevation, caffeine reduction, pelvic floor muscle exercises, and/or use of pharmacotherapy. ${ }^{7}$ Although oral anticholinergics (with muscarinic receptor antagonist activity) are often used to treat nocturia arising from $O A B$, several studies of anticholinergics have failed to demonstrate a benefit for nocturia. ${ }^{8}$ In studies 
in which anticholinergics have shown benefit, only a modest reduction of 0.3 to 0.7 fewer nocturic episodes per night were observed compared with placebo. ${ }^{9-11}$ Furthermore, anticholinergics have the potential to cause adverse events such as dry mouth, constipation, cognitive and functional impairment, risk of falls, and in some cases, all-cause death, which can be pronounced in certain patient subsets, particularly the elderly and those with specific medical conditions. ${ }^{12-16}$

Despite the potential for nocturia to aggravate poor health outcomes, the economic burden of nocturia, including its direct and indirect costs to patients and payers, has not been well documented in the literature. This study sought to assess differences in health care resource utilization (HCRU), health care costs, and work productivity in adult patients with differing frequencies of nocturia episodes (i.e., $<2$ vs. $\geq 2$ nocturia episodes per night).

\section{Methods}

\section{Study Design and Population}

This study utilized data collected through patient surveys and health care claims from patients enrolled in DaVita Medical Group (DMG), a physician-owned group that contracts with numerous health plans to provide primary and specialty care to $>600,000$ patients in the greater Los Angeles area. DMG maintains an integrated database containing deidentified and Health Insurance Portability and Accountability Act-compliant medical (outpatient and inpatient) and pharmacy claims.

Patients were continuously enrolled and identified from medical claims submitted between October 2013 and August 2014 and enrolled between April and August 2014. Patients aged $\geq 18$ years were included in the study if they were enrolled with DMG; had a claim during the 6-month pre-enrollment period with one of the following International Classification of Diseases, Ninth Revision, Clinical Modification (ICD-9-CM) codes: 788.43 (nocturia), 596.51 (OAB), or 600.0x (benign prostatic hypertrophy); self-reported having nocturia (e.g., defined as waking $\geq 1$ time per night to void) for $\geq 6$ months $^{1}$; were fluent in English or Spanish; and were willing and able to provide informed consent. Patients were excluded if they self-reported having diabetes insipidus over the past 6 months; a daily fluid intake exceeding 3,000 mL (12 glasses) during waking hours over the last 6 months; a history of restless leg syndrome; or work or lifestyle activities that interfered with nighttime sleep every night (Appendix A, available in online article).

Once enrolled, patients were administered a l-time survey for their sociodemographic information (including gender, marital status, employment status, education level, insurance type, and prescription drug coverage) and nocturia characteristics (number of nocturia episodes per night); a validated work productivity questionnaire; a validated generic quality of life survey (EuroQoL-5 Dimensions [EQ-5D]); and a nonvalidated nocturia-specific questionnaire. The EQ-5D and nocturia- specific survey data were not analyzed as they were not included in this report. For mailed surveys, the patient answered the questions themselves. For surveys conducted inoffice and via phone, project coordinators were trained to assist the subject in understanding the question but in no way guide them toward a particular response. There were 2 project coordinators involved with this project, and both received training in administering surveys.

Patient HCRU and costs were collected via claims data during the 6 months before enrollment. Claims data were collected retrospectively on potential patients (which had included cost information), with patients then being selected (i.e., continuously enrolled) and followed prospectively to determine the rate of nocturic episodes, with that data then linked back to the costs information that had been available through the databases.

For medical claims (e.g., outpatient and emergency department $[E D]$ ), we reported the approved cost by the payer. For prescription claims, we reported the paid amount by the payer, which was equal to the ingredient cost plus fees and minus any copay. For inpatient costs (e.g., hospitalizations), we used 2 methods: (1) Agency for Healthcare Research and Quality (AHRQ; for hospitalizations) and MedPAC (for skilled nursing facilities) based on age and diagnosis and (2) HealthCare Partners capitated per-diem rate for hospitalizations or skilled nursing facilities, which were within $10 \%$ or less of each other. The understanding, however, was that AHRQ/MedPAC was more generalizable, so for the purpose of this study, it was decided to proceed with the first option. Institutional review board/ethics committee approval was obtained.

\section{Outcomes Assessments}

Several outcomes were assessed and reported for patients with $<2$ versus $\geq 2$ nocturia episodes per night, including HCRU, health care costs, and work productivity. Our decision to categorize groups according to $<2$ versus $\geq 2$ nocturia episodes per night was in accordance with others who defined nocturia as being clinically significant at $\geq 2$ voids per night. ${ }^{2}$ All-cause HCRU and health care costs were assessed using medical and pharmacy claims. HCRU was reported as the mean number of visits per patient per month (PPPM) for outpatient encounters (all claims occurring in an outpatient setting including physician office visits, day surgeries, and laboratory and diagnostic procedures) and physician office visits only. Likewise, prescriptions filled were reported as the mean number of prescriptions filled PPPM. Additionally, the proportion of patients with $\geq 1$ hospitalization and $\geq 1$ ED visit in the previous 6 months before the enrollment date were reported. Health care costs, measured as total amount paid by the payer and patient, were inflated to 2015 U.S. dollars (USD) using a general consumer price index and were reported as mean PPPM costs for outpatient encounters, physician office visits, prescriptions filled, hospitalizations, and ED visits. 
Work productivity was assessed via the Work Productivity and Activity Impairment (WPAI) for nocturia questionnaire, a frequently used patient-reported outcome instrument that has been validated in patients with nocturia. ${ }^{17-19}$ The WPAI for nocturia questionnaire consists of 4 subscale scores, including absenteeism (the number of hours of work missed), presenteeism (the number of hours that nocturia affected productivity while at work), overall work impairment (sum of absenteeism and presenteeism), and activity impairment (how much nocturia affected daily nonwork-related activities), during a recall period of 1 week. The absenteeism, presenteeism, and overall work impairment subscales were only asked of patients who were employed, whereas the activity (nonwork-related) impairment subscale was asked of all patients regardless of employment status. Mean percentages were reported for absenteeism, presenteeism, overall work impairment, and activity impairment. ${ }^{20}$ Furthermore, using methods described elsewhere, absenteeism, presenteeism, and overall work impairment results were converted into and reported as mean differences in work days lost PPPM and indirect costs PPPM between the 2 groups. ${ }^{21,22}$

\section{Statistical Methods}

Demographic, comorbid, and nocturia characteristics were reported descriptively and compared for patients with $<2$ versus $\geq 2$ nocturia episodes per night using chi-square tests for categorical variables and t-tests for interval variables. For demographics, patients self-reported at enrollment date their race, marital status, employment status, education level, annual household income, ZIP code, height, weight, insurance type, and prescription drug coverage. For comorbidities, claims data were analyzed using ICD-9-CM codes for 6 months before enrollment. For nocturia characteristics, patients self-reported those measures.

Multivariate modeling was employed to examine the association between the frequency of nocturia episodes and HCRU, costs, and work productivity. HCRU outcomes were modeled using negative binomial regressions, with the exception of hospitalizations and ED visits, which were modeled using logistic regression. Health care cost outcomes were modeled using generalized linear regression models with a gamma distribution and $\log$ link, with the exception of prescription, hospitalization, and ED costs, which were modeled using 2-part models (logistic regression followed by a generalized linear model with gamma distribution and log link) to account for the large proportion of patients with zero costs in these categories.

Work productivity outcomes were modeled using 2-part regression techniques with the first part employing a logistic regression and the second part using a binomial regression approach, with an exception for absenteeism, where we found that the absenteeism results were so dissimilar between patients with $<2$ versus $\geq 2$ nocturia episodes that the model would not converge. A list of potential confounders was created a priori by soliciting expert opinion and was included in all adjusted models for all outcomes assessed in this study. These confounders included Charlson Comorbidity Index scores (derived via medical claims data), age, sex, education, employment status, insurance type, treatment with nocturiarelated medication, marital status, anxiety, depression, asthma, $\mathrm{OAB}$, urinary incontinence, benign prostatic hypertrophy, falls and fractures, and insomnia, all of which were derived from the patient self-reported questionnaire..$^{23}$ Variables within a backward-stepwise regression model that displayed a $P$ value $<0.20$ were retained for adjustment in the subsequent models. Statistical analyses were conducted using STATA version 14 (StataCorp, College Station, TX). All models assumed robust standard errors and determined statistical significance at a $P$ value $<0.05$

\section{Results}

\section{Study Population}

A total of 899 patients were enrolled in this study. In general, patients in the study sample tended to be older (mean age: 71.4 years), predominantly retired (71.6\%), and male (57.2\%). Of the study patients, 197 (21.9\%) reported having $<2$ nocturia episodes per night, with the remaining 702 (78.1\%) having $\geq 2$ nocturia episodes per night. Compared with patients who had $<2$ nocturia episodes per night, those with $\geq 2$ nocturia episodes per night were older, were more likely to be single and retired, and presented more often with comorbidities including chronic obstructive pulmonary disease, insomnia, $\mathrm{OAB}$, and urinary incontinence (Table 1).

\section{Health Care Resource Utilization}

Compared with patients who experienced fewer nocturia episodes, those with $\geq 2$ nocturia episodes per night had significantly more outpatient encounters (unadjusted mean visits PPPM: 2.1 vs. 1.6; $P<0.001$; adjusted mean visits PPPM: 2.1 vs. 1.6; $P=0.017$ ) and office visits (unadjusted and adjusted mean visits PPPM: 0.9 vs. 0.7; $P<0.001$; Figure $1 \mathrm{~A}-\mathrm{B}$ ). Patients with $\geq 2$ nocturia episodes per night also had a $7.6 \%$ versus $4.6 \%$ $(P=0.163)$ unadjusted rate of hospitalization within the past 6 months and an $8.1 \%$ versus $4.4 \%(P=0.263)$ adjusted proportion of hospitalization within the past 6 months, respectively, compared with those who experienced $<2$ nocturia episodes per night. In addition, those with $\geq 2$ nocturia episodes per night had a $16.9 \%$ versus $14.9 \%(P=0.510)$ unadjusted proportion of ED visits within the past 6 months and a 17.1\% versus $14.9 \%(P=0.722)$ adjusted rate of ED visits within the past 6 months compared with those with $<2$ nocturia episodes per night; however, differences in hospitalizations and ED visits between the nocturia groups were not statistically significant (Figure 1A-B). Patients with $\geq 2$ nocturia episodes per night had a higher number of prescriptions filled compared with 


\begin{tabular}{|c|c|c|c|}
\hline \multirow{2}{*}{ Characteristic } & $\begin{array}{l}\text { raphic an } \\
\text { teristics of } \\
\geq 2 \text { Noctu }\end{array}$ & $\begin{array}{l}\text { linical } \\
\text { tients wit } \\
\text { Episodes }\end{array}$ & 2 \\
\hline & $\begin{array}{c}<2 \text { Nocturia } \\
\text { Episodes } \\
(\mathrm{n}=197)\end{array}$ & $\begin{array}{c}\geq 2 \text { Nocturia } \\
\text { Episodes } \\
(\mathbf{n}=702)\end{array}$ & \multirow{2}{*}{$\frac{P \text { Value }^{\mathrm{a}}}{<0.001}$} \\
\hline Age, mean (SD), years & $65.1 \quad(15.4)$ & $73.2(11.8)$ & \\
\hline \multicolumn{4}{|l|}{ Sex, n (\%) } \\
\hline Female & $80 \quad(40.6)$ & $276 \quad(39.3)$ & 0.308 \\
\hline Male & $114(57.9)$ & $400 \quad(57.0)$ & \\
\hline Missing & $3 \quad(1.5)$ & $26 \quad(3.7)$ & \\
\hline \multicolumn{4}{|l|}{ Marital status, n (\%) } \\
\hline Married/living together & $126(64.0)$ & $383(54.6)$ & 0.006 \\
\hline Single & $67(34.0)$ & $315(44.9)$ & \\
\hline No answer & $4 \quad(2.0)$ & $4 \quad(0.6)$ & \\
\hline Education, n (\%) & & & 0.057 \\
\hline $\begin{array}{l}\text { Less than high school } \\
\text { diploma }\end{array}$ & $27(13.7)$ & 134 (19.1) & \\
\hline High school graduate & $87(44.2)$ & $338(48.1)$ & \\
\hline 4-year college degree & $51 \quad(25.9)$ & $139(19.8)$ & \\
\hline $\begin{array}{l}\text { Graduate/postgraduate } \\
\text { degree }\end{array}$ & $26(13.2)$ & $62 \quad(8.8)$ & \\
\hline No answer & $6 \quad(3.0)$ & $29 \quad(4.1)$ & \\
\hline Employment, n (\%) & & & $<0.001$ \\
\hline Retired & $101 \quad(51.3)$ & $543(77.4)$ & \\
\hline Employed & $77 \quad(39.1)$ & $123(17.5)$ & \\
\hline $\begin{array}{l}\text { Unemployed, but not } \\
\text { retired }\end{array}$ & $17 \quad(8.6)$ & $36 \quad(5.1)$ & \\
\hline No answer & $2 \quad(1.0)$ & $0 \quad(0.0)$ & \\
\hline Insurance, n (\%) & & & $<0.001$ \\
\hline HMO/PPO/POS (employer) & $95(48.2)$ & $177(25.2)$ & \\
\hline Medicaid/Medicare & $84 \quad(42.6)$ & $448 \quad(63.8)$ & \\
\hline $\begin{array}{l}\text { Private insurance } \\
\text { (self-purchased) }\end{array}$ & $7 \quad(3.6)$ & $10 \quad(1.4)$ & \\
\hline No insurance coverage & $0 \quad(0.0)$ & $4 \quad(0.6)$ & \\
\hline Not reported/missing & $11 \quad(5.6)$ & $63 \quad(9.0)$ & \\
\hline CCI score, n (\%) & & & $<0.001$ \\
\hline 0 & $115(58.4)$ & $300 \quad(42.7)$ & \\
\hline 1 & $13 \quad(6.6)$ & $75(10.7)$ & \\
\hline$\geq 2$ & $66 \quad(33.5)$ & $298 \quad(42.5)$ & \\
\hline Not reported/missing & $3 \quad(1.5)$ & $29 \quad(4.1)$ & \\
\hline \multicolumn{4}{|l|}{ Comorbidities, n (\%) } \\
\hline Anxiety & $29 \quad(14.7)$ & $129(18.4)$ & 0.234 \\
\hline Asthma & $22(11.2)$ & $65 \quad(9.3)$ & 0.423 \\
\hline $\mathrm{BPH}$ & $43(21.8)$ & $141 \quad(20.1)$ & 0.592 \\
\hline COPD & $7 \quad(3.6)$ & $63 \quad(9.0)$ & 0.012 \\
\hline Depression & $43 \quad(21.8)$ & $146(20.8)$ & 0.754 \\
\hline Fractures from falls & $16 \quad(8.1)$ & $67 \quad(9.5)$ & 0.542 \\
\hline Heart disease & $35(17.8)$ & $159(22.6)$ & 0.141 \\
\hline Insomnia & $25(12.7)$ & $134(19.1)$ & 0.038 \\
\hline $\mathrm{OAB}$ & $62(31.5)$ & $306 \quad(43.6)$ & 0.002 \\
\hline Urinary incontinence & $58 \quad(29.4)$ & $263(37.5)$ & 0.038 \\
\hline \multicolumn{4}{|c|}{$\begin{array}{l}\text { aP values were obtained from a 2-sample t-test of means with unequal variances for } \\
\text { age and chi-square tests for categorical variables. } \\
B P H=\text { benign prostatic hypertrophy; } C C I=C \text { Charlson Comorbidity Index; } \\
C O P D=\text { chronic obstructive pulmonary disease; } H M O=\text { health maintenance } \\
\text { organization; OAB = overactive bladder; } P O S=\text { point of service; } P P O=\text { preferred } \\
\text { provider organization; } S D=\text { standard deviation. }\end{array}$} \\
\hline
\end{tabular}

those who experienced fewer nocturia episodes (unadjusted mean prescription fills PPPM: 3.1 vs. 2.1, $P<0.001$; adjusted mean prescription fills PPPM: 3.2 vs. $2.2, P=0.027$ ).

\section{Health Care Costs}

In Figure 2A-B, patients with $\geq 2$ nocturia episodes per night demonstrated significantly higher health care costs for outpatient encounters (unadjusted mean PPPM costs: $\$ 676$ vs. $\$ 516$, $P=0.028$; adjusted mean PPPM costs: $\$ 678$ vs. $\$ 506, P=0.017$, respectively, when compared with those who experienced $<2$ nocturia episodes per night. While the unadjusted cost of office visits for patients with $\geq 2$ nocturia episodes per night was $\$ 106$ vs. $\$ 79$ for patients with $<2$ nocturia episodes per night $(P<0.0001)$, the adjusted cost of office visits was $\$ 107$ for patients with $\geq 2$ nocturia episodes versus $\$ 78$ for patients with $<2$ nocturia episodes $(P=0.084)$. In addition, unadjusted overall health care cost for patients with $\geq 2$ nocturia episodes per night was $\$ 1,144$ versus $\$ 798$ for patients with $<2$ nocturia episodes $(P=0.060)$, and adjusted cost for patients with $\geq 2$ nocturia episodes per night was $\$ 1,114$ versus $\$ 810$ for patients with $<2$ nocturia episodes $(P=0.038)$. Unadjusted and adjusted health care costs did not differ appreciably between nocturia groups for prescriptions filled, hospitalizations, or ED visits.

\section{Work Productivity}

Patients with $\geq 2$ nocturia episodes per night were found to experience greater productivity impairment when at work compared with those exhibiting $<2$ nocturia episodes per night (Appendix B, available in online article). Notably, patients with $\geq 2$ nocturia episodes per night lost an estimated unadjusted and adjusted 2.2 more days PPPM (26.4 days per patient per year) due to diminished work productivity compared with patients who experienced $<2$ nocturia episodes per night. As a result of these lost work days, patients with $\geq 2$ nocturia episodes per night had an estimated indirect cost of $\$ 347$ more PPPM $(\$ 4,164$ per patient per year; $P<0.001)$ than patients with $<2$ nocturia episodes per night. Patients with a higher nocturia frequency also reported a significantly greater unadjusted and adjusted impairment in their daily activities (i.e., $22 \%$ vs. $12 \% ; P=0.001$ ).

\section{Discussion}

This study examined the economic burden of nocturia. HCRU and related costs, in addition to work productivity and activity impairment, were compared among adult patients with differing frequencies of nocturia episodes. Compared with patients who reported $<2$ nocturia episodes per night, those with $\geq 2$ nocturia episodes per night exhibited greater unadjusted and adjusted outpatient-related HCRU, which was significant for all outpatient encounters, the subset of physician office visits, and the number of prescriptions filled. Based on these outpatient- 
FIGURE 1 Unadjusted and Adjusted Measures of HCRU (with 95\% Cls) for Patients with $<2$ Versus $\geq 2$ Nocturia Episodes per Night According to the Proportion of Patients with Hospitalizations and ED Visits and Number of Office Visits, Outpatient Encounters, and Prescriptions Filled

A. Unadjusted Measures

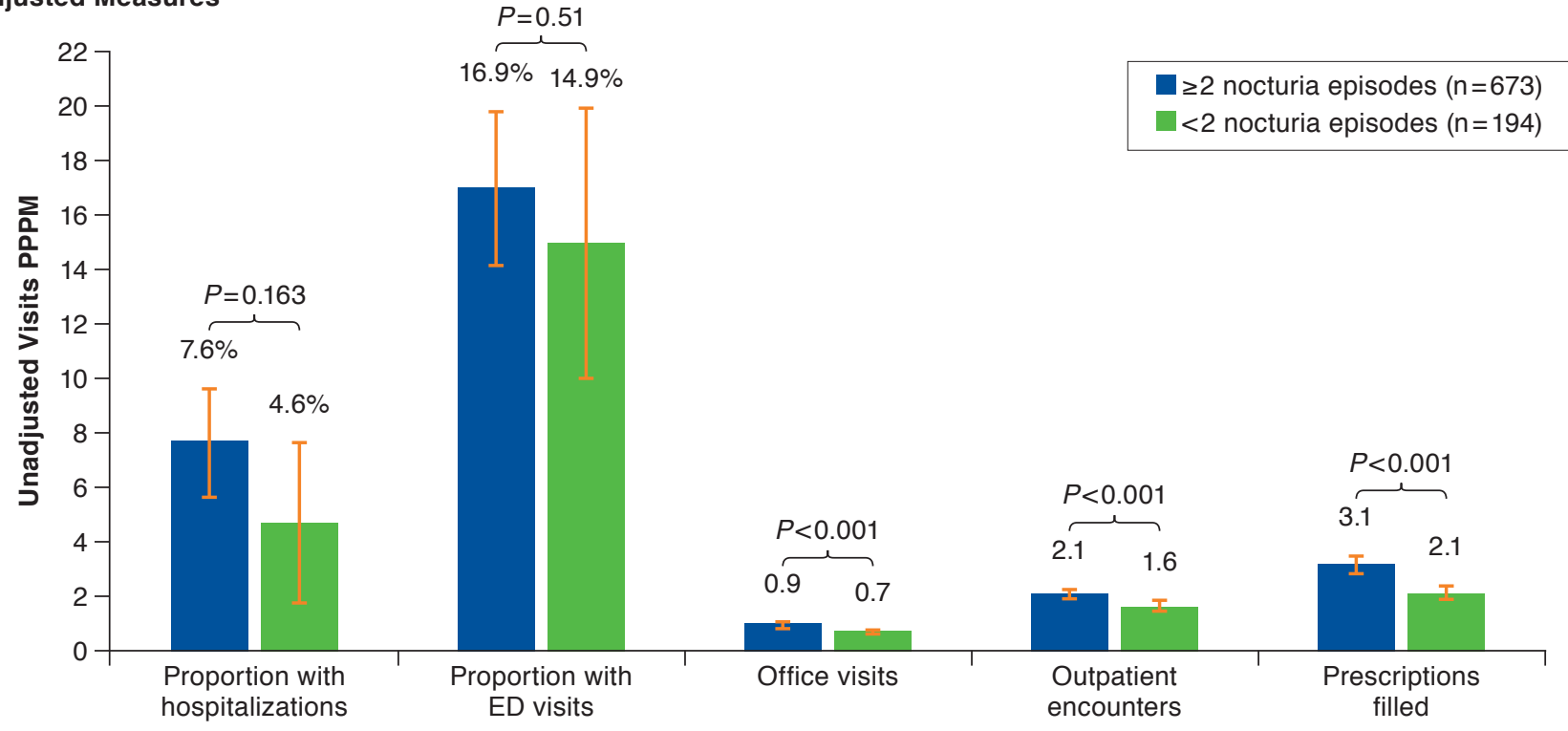

\section{B. Adjusted Measures ${ }^{a}$}

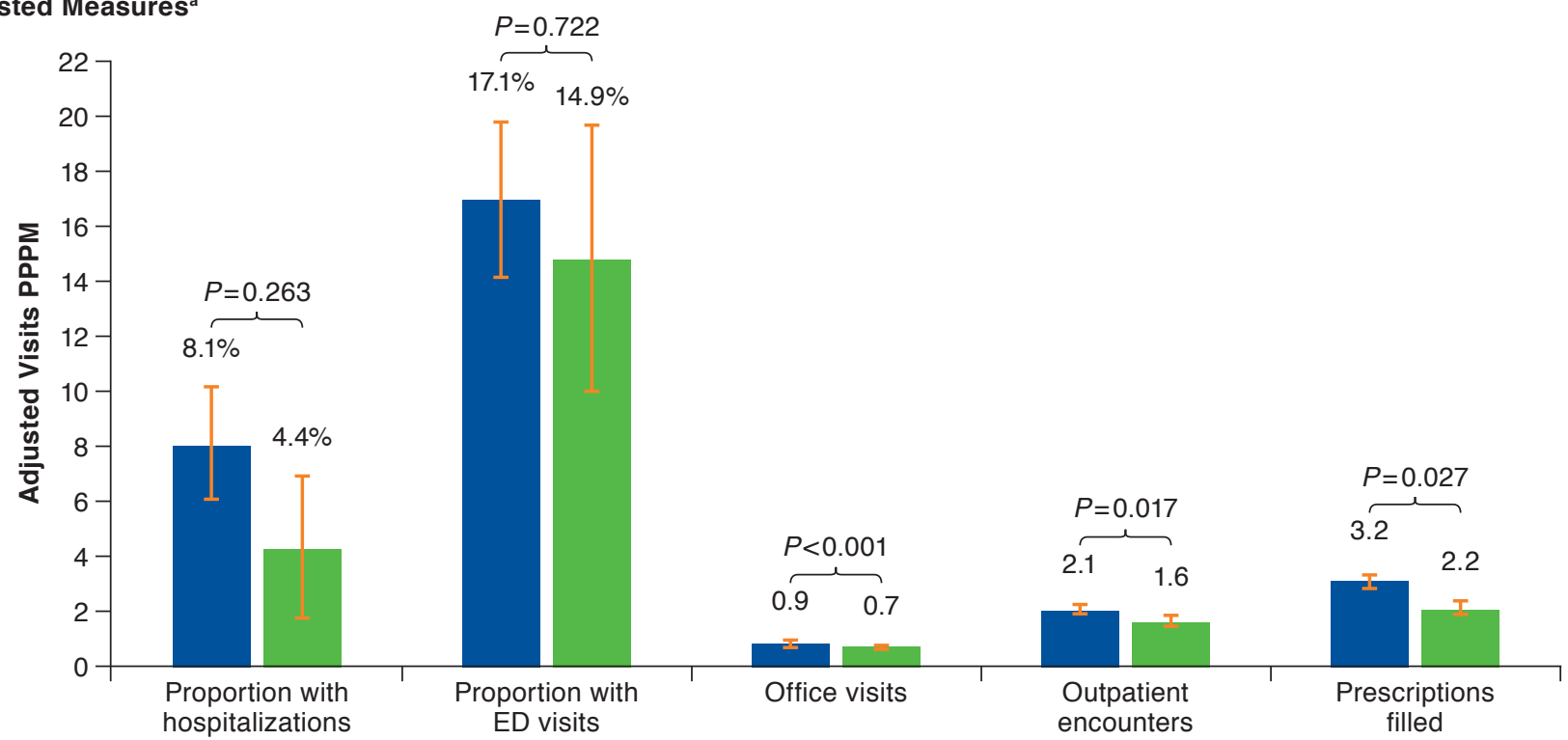

aVariables retained for adjustment were age, sex, overactive bladder, and benign prostatic hypertrophy. Adjusted proportions were estimated using logistic regression with robust standard errors. Otherwise, adjusted estimates were calculated from negative binomial regression using robust standard errors. "Outpatient encounters" comprised all outpatient visits, including but not limited to physician office visits, day surgeries, and diagnostic procedures.

$C I=$ confidence interval; $E D=$ emergency department; HCRU = health care resource utilization; $P P P M=$ per patient per month.

related HCRU trends, patients who experienced $\geq 2$ nocturia episodes per night also incurred higher unadjusted and adjusted outpatient health care-related costs. Statistically significantly higher costs were not consistently observed between unadjusted and adjusted findings for office visit costs and total costs between the 2 groups. However, patients with $\geq 2$ nocturia episodes reported greater impairment in unadjusted and adjusted work productivity and in their daily activities. 
FIGURE 2 Unadjusted and Adjusted Medical Costs (with 95\% Cls) Based on HCRU for Patients with $<2$ Versus $\geq 2$ Nocturia Episodes per Night

\section{A. Unadjusted Medical Costs}

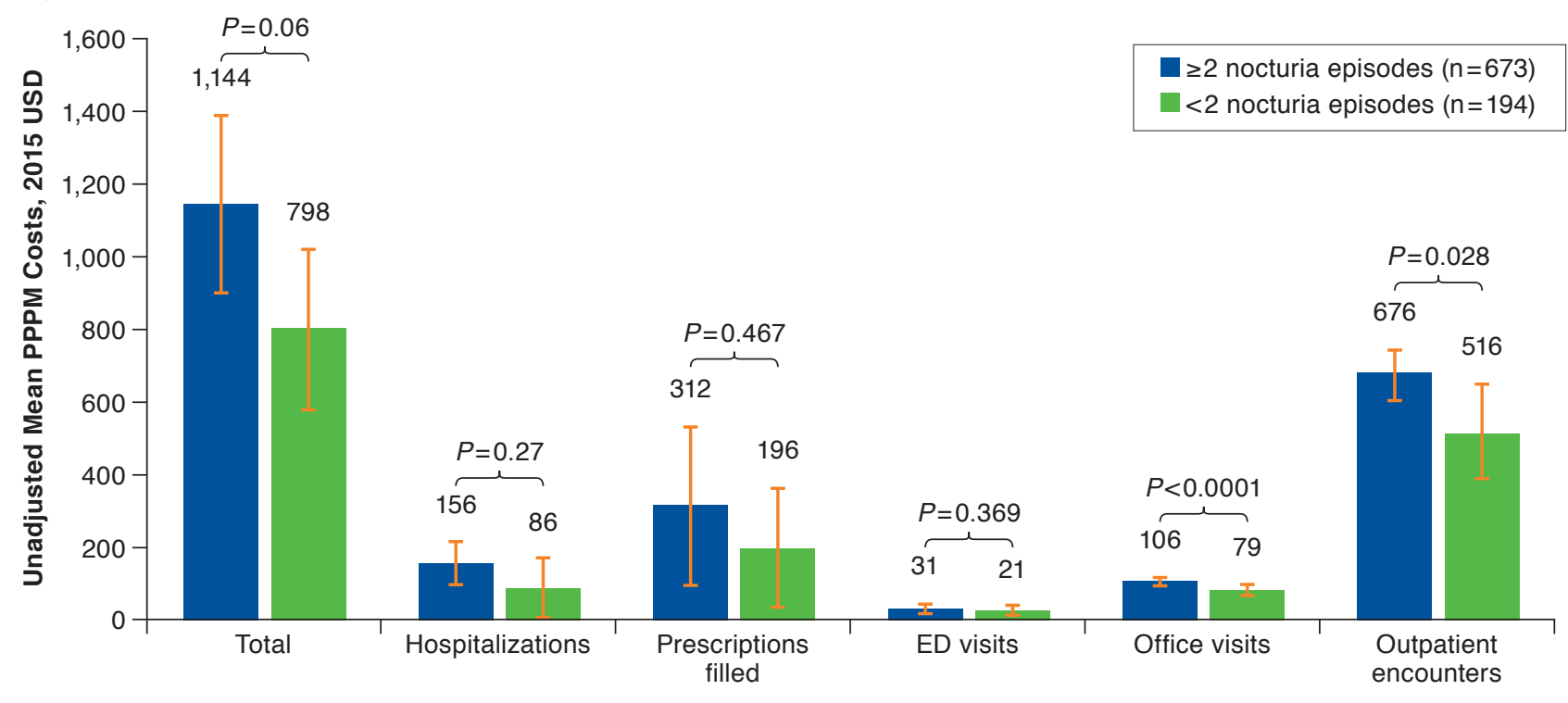

\section{B. Adjusted Medical Costs ${ }^{a}$}

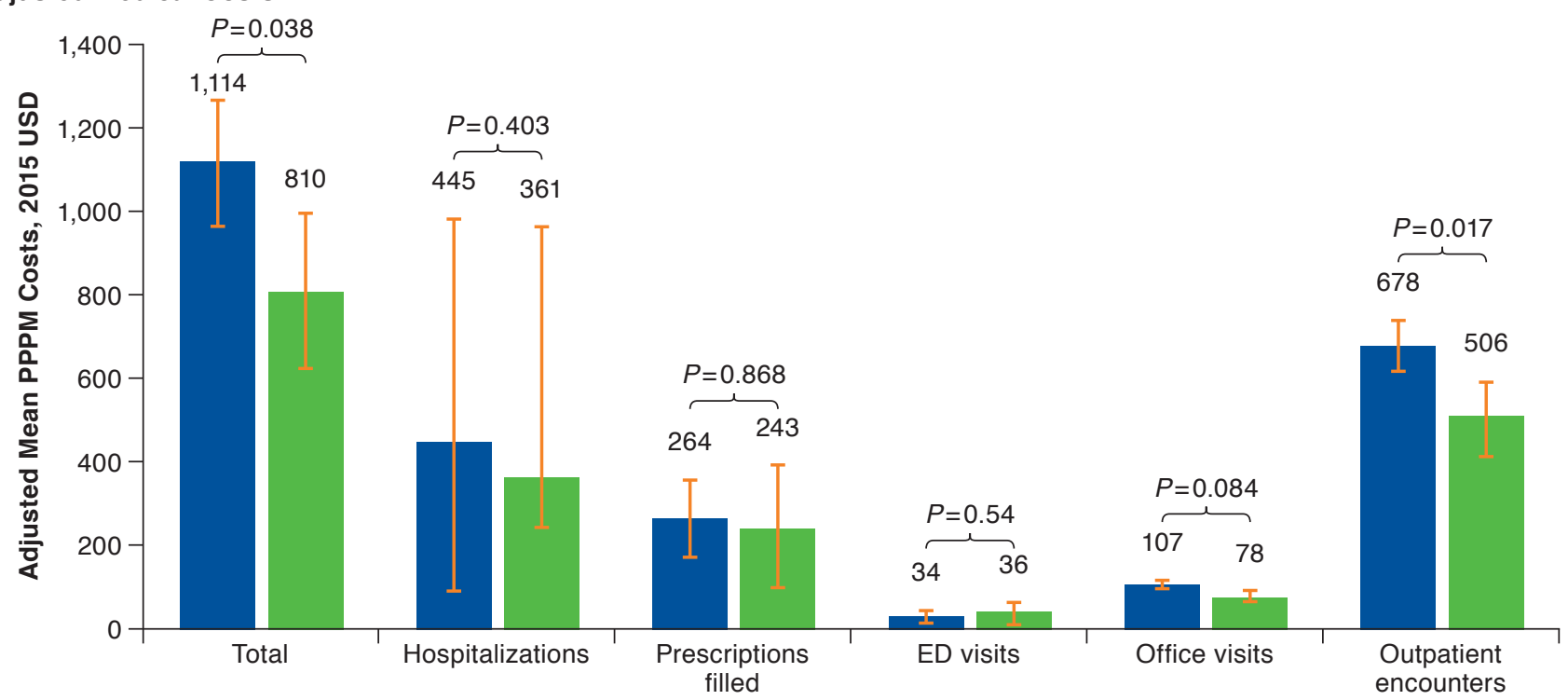

aVariables retained for adjustment were age, sex, overactive bladder, and benign prostatic hypertrophy.

$C I=$ confidence interval; $E D=$ emergency department; HCRU = health care resource utilization; PPPM = per patient per month; USD=U.S. dollars.

When comparing direct per-patient costs, extrapolation of the observed PPPM outpatient encounter cost estimates from the current investigation to annual costs (i.e., adjusted mean outpatient annual PPPM cost $=\$ 678$ USD multiplied by 12 months) yields a mean outpatient cost of nocturia of approximately $\$ 8,136$ USD per patient each year, which is slightly higher than the approximately $\$ 7,562$ USD annual outpatient encounter cost (from physician office visits and other outpatient services such as diagnostic tests and laboratory or radiology services) per patient that has been reported for irritable bowel syndrome. ${ }^{24}$ Irritable bowel syndrome is considered one of the top 10 causes of patient consultation with a primary care 
physician. ${ }^{25}$ Previous reports have documented the concomitant relationship between irritable bowel syndrome and bladder symptoms such as $\mathrm{OAB}$ (that includes nocturia), rendering these comparisons of particular interest given that nocturia appears to accrue a higher cost of illness than a more recognized condition, yet is frequently overlooked as an important standalone and treatable medical condition. ${ }^{26}$

To date, the general lack of published studies reporting the costs of illness arising from nocturia has represented a fundamental challenge toward understanding the socioeconomic consequences of this disorder. One investigation calculated that individuals with nocturia incur a total direct and indirect annual cost of around $\$ 62.5$ billion USD (conservative estimate). ${ }^{27}$ A large share of these costs is a consequence of decreased productivity (i.e., $\$ 61$ billion USD), underlining the high societal and economic burden of nocturia.

As documented in this study and observed by others, nocturia can account for substantial overall work impairment by disrupting work productivity and increasing the rate of absenteeism among those in the workforce. ${ }^{17,28-30}$ The attenuation in work productivity is most likely afforded to the negative health consequences of nocturia, primarily sleep deterioration during nighttime, daytime sleepiness, and mood disturbance, which can consequently influence employability, earning potential, and job stability among those with nocturia. ${ }^{5,6,31}$ Continuing research in this area is needed to support and extend our understanding of this highly bothersome disorder.

\section{Limitations}

The rates and frequencies of nocturic episodes were ascertained over a 6-month period following measurement of HCRU and cost outcomes. Therefore, any association observed between the frequency of nocturic episodes and economic outcomes involved the assumption that the frequency of nocturic episodes was equivalent in the 6 months before assessment, when HCRU and cost information were collected. A higher prevalence of comorbid conditions was observed among those with $\geq 2$ nocturic episodes per night. Thus, we cannot discount the possibility that the higher outpatient-related HCRU also documented in this subset of patients could have been attributable to other underlying illnesses beyond nocturia. Although this study encompassed a predominantly older, retired population, which is characteristic of the larger population of patients with nocturia, the data were collected specifically from patients who resided in the greater Los Angeles region; hence, the present study findings may not be generalizable on a national scale.

\section{Conclusions}

The results from this study indicate that nocturia was associated with higher outpatient encounters and related costs among patients with a greater frequency of nocturic episodes. Understanding the costs that may be accrued from this condition will help underscore the financial and health impacts that nocturia can potentially inflict on patients, health care systems, and society.

\section{Authors}

ROGER DMOCHOWSKI, MD, Vanderbilt University Medical Center, Nashville, Tennessee; BENJAMIN M. BRUCKER, MD, New York University, Langone Health, New York, New York; and EMILY COLE, MD, Sharp Rees-Stealy Medical Group, San Diego, California. STEVE KAWAHARA, PharmD, BCACP, and RIYA PULICHARAM, MD, DaVita Medical Group, El Segundo, California. CAROLINE BURK, PharmD, MS, Health Outcomes Consultant, Laguna Beach, California; AMY TUNG, PharmD, MS, Allergan, plc, Irvine, California; and DOUGLASS HALE, MD, Urogynecology Associates, Indianapolis, Indiana

AUTHOR CORRESPONDENCE: Amy Tung, PharmD, MS, Global Health Economics and Outcomes Research, Allergan plc, 2525 Dupont Dr. (T2-2P), Irvine, CA 92612-1599.

Tel.: 714.246.5669; E-mail: Amy_Tung@Allergan.com.

\section{DISCLOSURES}

This study was funded by Allergan plc, Dublin, Ireland. Neither honoraria nor payments were provided for authorship. Dmochowski is a consultant and speaker for Allergan plc and a consultant for Serenity Pharmaceuticals. Brucker is a consultant and speaker for Allergan plc, a consultant for WatkinsConti and Avadel, and an investigator for Medtronic and Ipsen. Cole is a consultant for Allergan plc and an employee of Sharp Rees-Stealy Medical Group. Kawahara and Pulicharam are full-time employees of DaVita Medical Group. Burk is a consultant for Allergan plc and a health outcomes consultant. Tung is an employee of Allergan plc. Hale has served as a consultant/advisor to and has received research funding from Allergan plc.

The data from this manuscript were previously presented in poster format by Steve Kawahara at the Academy of Managed Care \& Specialty Pharmacy Annual Meeting; April 19-22, 2016; San Francisco, CA.

\section{ACKNOWLEDGMENTS}

Editorial assistance was provided by Bríain Ó. Hartaigh, PhD, and Karen E. Smoyer, PhD, of Evidence Scientific Solutions, Philadelphia, PA, and funded by Allergan plc.

\section{REFERENCES}

1. Van Kerrebroeck PE, Dmochowski R, FitzGerald MP, et al. Nocturia research: current status and future perspectives. Neurourol Urodyn. 2010;29(4):623-28.

2. Tikkinen KA, Johnson TM 2nd, Tammela TL, et al. Nocturia frequency, bother, and quality of life: how often is too often? A population-based study in Finland. Eur Urol. 2010;57(3):488-96

3. Kupelian V, Fitzgerald MP, Kaplan SA, Norgaard JP, Chiu GR, Rosen RC. Association of nocturia and mortality: results from the Third National Health and Nutrition Examination Survey. J Urol. 2011;185(2):571-77.

4. Van Kerrebroeck P, Abrams P, Chaikin D, et al. The standardisation of terminology in nocturia: report from the Standardisation Sub-committee of the International Continence Society. Neurourol Urodyn. 2002;21(2):179-83.

5. Bosch JL, Weiss JP. The prevalence and causes of nocturia. J Urol. 2013;189(1 Suppl):S86-92.

6. Asplund R. Nocturia: consequences for sleep and daytime activities and associated risks. Eur Urol Suppl. 2005;3(6):24-32. 
7. Johnson TM. Nocturia: clinical presentation, diagnosis, and treatment. Givens J, ed. UpToDate. Last updated August 9, 2018. Retrieved February 15, 2018. Available at: https://www.uptodate.com/contents/nocturia-clinical-presentation-evaluation-and-management-in-adults. Accessed January 11, 2019.

8. Diokno AC, Brown MB, Goldstein NG, Herzog AR. Urinary flow rates and voiding pressures in elderly men living in a community. J Urol. 1994;151(6):1550-53.

9. Cardozo L, Lisec M, Millard R, et al. Randomized, double-blind placebo controlled trial of the once daily antimuscarinic agent solifenacin succinate in patients with overactive bladder. J Urol. 2004;172(5 Pt 1):1919-24.

10. Johnson TM 2nd, Burgio KL, Redden DT, Wright KC, Goode PS. Effects of behavioral and drug therapy on nocturia in older incontinent women. J Am Geriatr Soc. 2005;53(5):846-50.

11. Yokoyama O, Yamaguchi O, Kakizaki H, et al. Efficacy of solifenacin on nocturia in Japanese patients with overactive bladder: impact on sleep evaluated by bladder diary. J Urol. 2011;186(1):170-74.

12. Skelly J. Review: anticholinergic drugs improve symptoms but increase dry mouth in adults with overactive bladder syndrome. Evid Based Nurs. 2003;6(2):49.

13. Fonseca AM, Meinberg MF, Monteiro MV, Roque M, Haddad JM, Castro RA. The effectiveness of anticholinergic therapy for overactive bladders: systematic review and meta-analysis. Rev Bras Ginecol Obstet. 2016;38(11):564-75.

14. Dauphinot V, Mouchoux C, Veillard S, Delphin-Combe F, Krolak-Salmon P Anticholinergic drugs and functional, cognitive impairment and behavioral disturbances in patients from a memory clinic with subjective cognitive decline or neurocognitive disorders. Alzheimers Res Ther. 2017;9(1):58.

15. Pasina L, Djade CD, Lucca U, et al. Association of anticholinergic burden with cognitive and functional status in a cohort of hospitalized elderly: comparison of the anticholinergic cognitive burden scale and anticholinergic risk scale: results from the REPOSI study. Drugs Aging. 2013;30(2):103-12.

16. Ruxton K, Woodman RJ, Mangoni AA. Drugs with anticholinergic effects and cognitive impairment, falls and all-cause mortality in older adults: a systematic review and meta-analysis. Br J Clin Pharmacol. 2015;80(2):209-20.

17. Kobelt G, Borgstrom F, Mattiasson A. Productivity, vitality and utility in a group of healthy professionally active individuals with nocturia. BJU Int. 2003;91(3):190-95

18. Sand PK, Dmochowski RR, Reddy J, van der Meulen EA. Efficacy and safety of low dose desmopressin orally disintegrating tablet in women with nocturia: results of a multicenter, randomized, double-blind, placebo controlled, parallel group study. J Urol. 2013;190(3):958-64.
19. Weiss JP, Herschorn S, Albei CD, van der Meulen EA. Efficacy and safety of low dose desmopressin orally disintegrating tablet in men with nocturia: results of a multicenter, randomized, double-blind, placebo controlled, parallel group study. J Urol. 2013;190(3):965-72.

20. Reilly MC, Zbrozek AS, Dukes EM. The validity and reproducibility of a work productivity and activity impairment instrument. Pharmacoeconomics. 1993;4(5):353-65

21. Brooks A, Hagen SE, Sathyanarayanan S, Schultz AB, Edington DW. Presenteeism: critical issues. J Occup Environ Med. 2010;52(11):1055-67.

22. U.S. Bureau of Labor Statistics. Highlights of women's earnings in 2014. Available at: https://www.bls.gov/opub/reports/womens-earnings/archive/ highlights-of-womens-earnings-in-2014.pdf. Accessed December 28, 2018.

23. Charlson ME, Pompei P, Ales KL, MacKenzie CR. A new method of classifying prognostic comorbidity in longitudinal studies: development and validation. J Chronic Dis. 1987;40(5):373-83.

24. Buono JL, Mathur K, Averitt AJ, Andrae DA. Economic burden of irritable bowel syndrome with diarrhea: retrospective analysis of a U.S. commercially insured population. J Manag Care Spec Pharm. 2017;23(4):453-60. Available at: https://www.jmcp.org/doi/10.18553/jmcp.2016.16138.

25. Hulisz D. The burden of illness of irritable bowel syndrome: current challenges and hope for the future. J Manag Care Pharm. 2004;10(4):299309. Available at: https://www.jmcp.org/doi/10.18553/jmcp.2004.10.4.299.

26. Matsumoto S, Hashizume K, Wada N, et al. Relationship between overactive bladder and irritable bowel syndrome: a large-scale internet survey in Japan using the overactive bladder symptom score and Rome III criteria. BJU Int. 2013;111(4):647-52.

27. Holm-Larsen T, Weiss JP, Langkilde LK. Economic burden of nocturia in the US adult population. J Urol. 2010;183(4):el.

28. Ohayon MM. Nocturnal awakenings and comorbid disorders in the American general population. J Psychiatr Res. 2008;43(1):48-54.

29. Andersson F, Anderson P, Holm-Larsen T, Piercy J, Everaert K, Holbrook T. Assessing the impact of nocturia on health-related qualityof-life and utility: results of an observational survey in adults. J Med Econ. 2016;19(12):1200-06.

30. Miller PS, Hill H, Andersson FL. Nocturia work productivity and activity impairment compared with other common chronic diseases. Pharmacoeconomics. 2016;34(12):1277-97.

31. Holm-Larsen T. The economic impact of nocturia. Neurourol Urodyn. 2014;33(Suppl 1):S10-14. 


\section{APPENDIX A Patient Identification Flowchart}

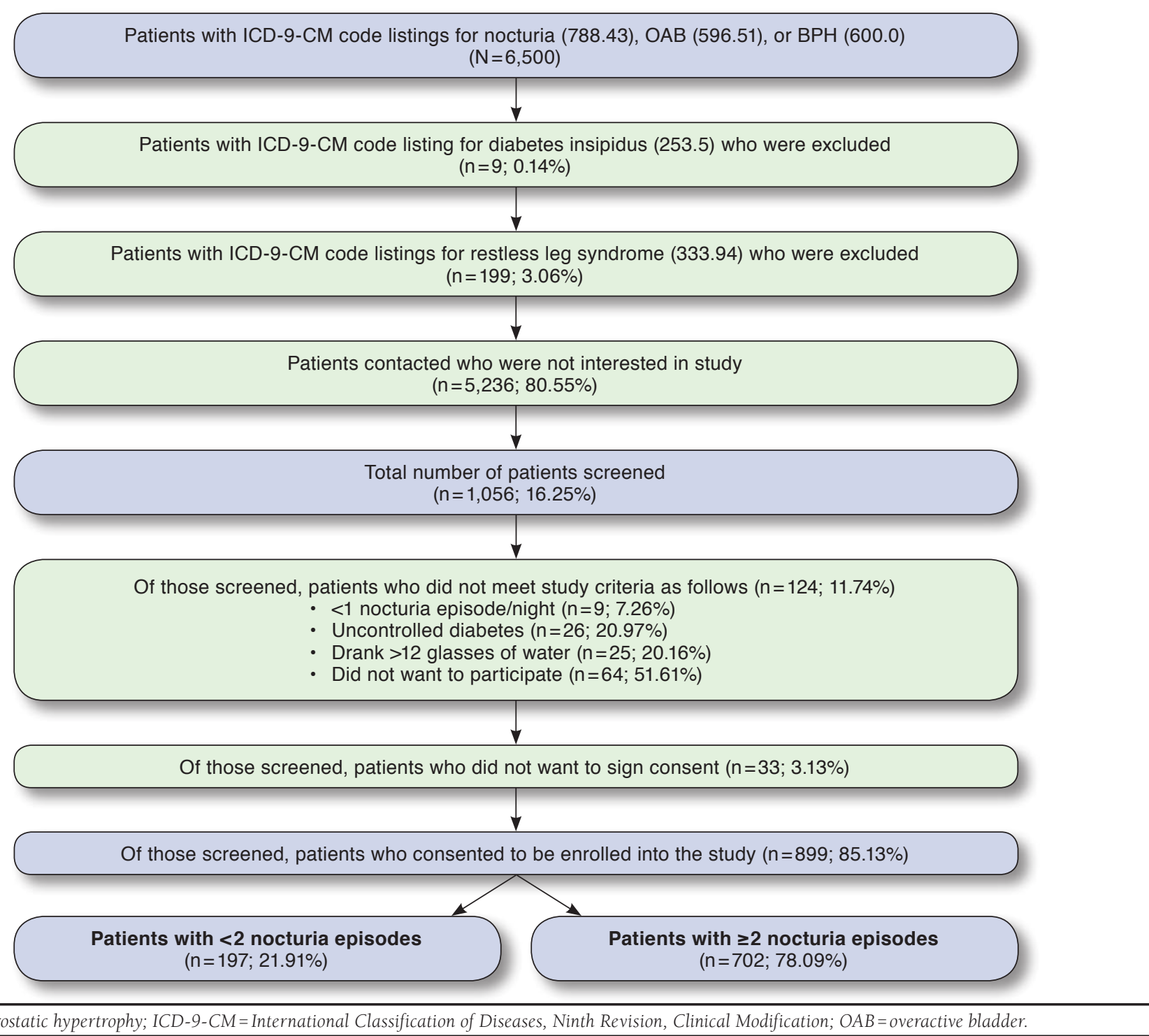


APPENDIX B Measures of Unadjusted and Adjusted Work Loss and Productivity Impairment (with 95\% Cls) for Patients with $<2$ Versus $\geq 2$ Nocturia Episodes per Night

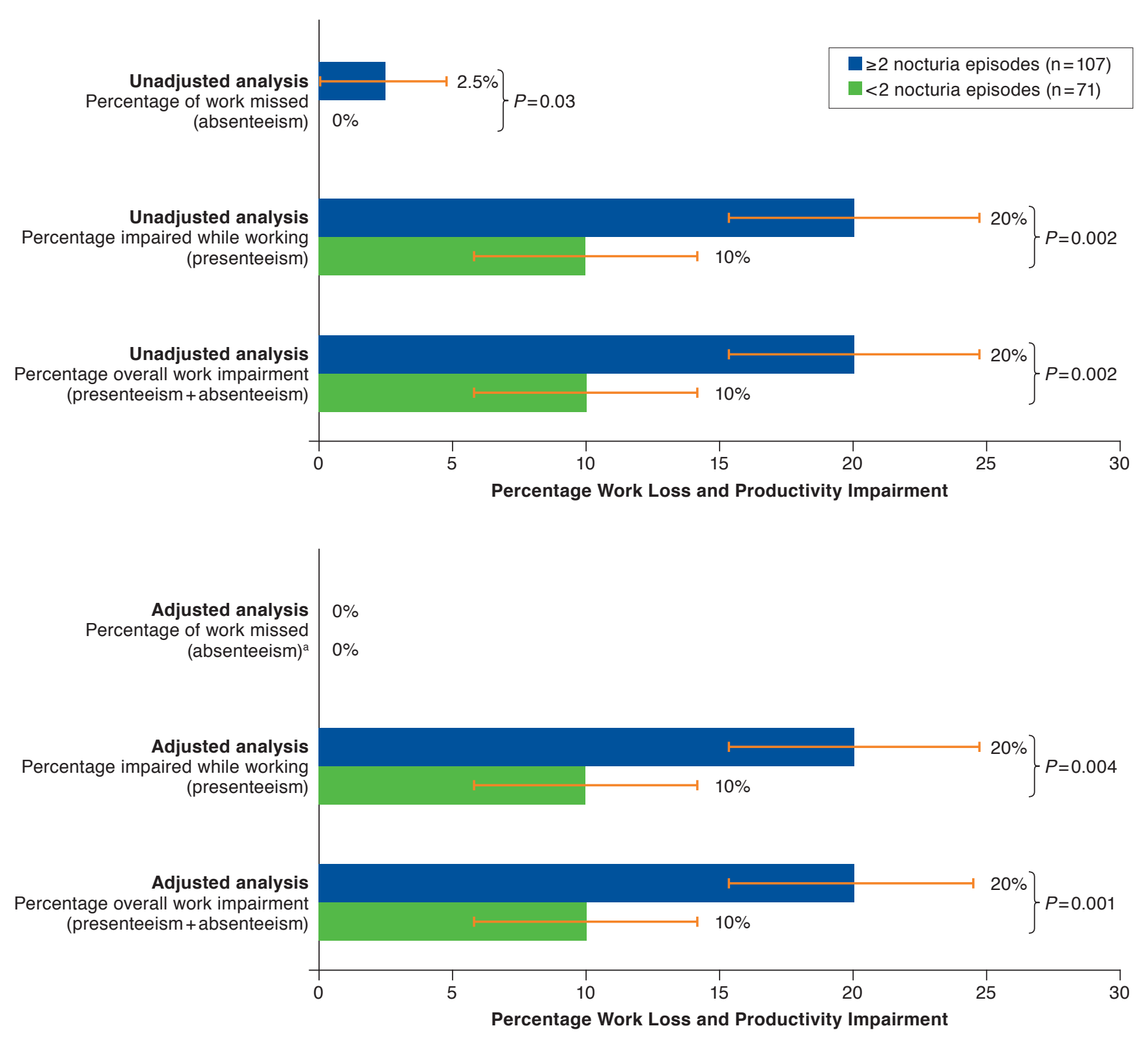

Note: Estimates were adjusted for age, sex, overactive bladder, and benign prostatic hypertrophy using a 2-part model of logistic regression followed by binomial regression with robust standard errors.

a Estimates were not adjusted owing to lack of overlap between nocturia frequency groups. 